\title{
Pharmacophagy in green lacewings (Neuroptera: Chrysopidae: Chrysopa spp.)?
}

Jeffrey R Aldrich, Kamal Chauhan, Qing-He Zhang

Green lacewings (Neuroptera: Chrysopidae) are voracious predators of aphids and other small, soft-bodied insects and mites. Earlier, we identified $(1 R, 2 S, 5 R, 8 R)$-iridodial from wild males of the goldeneyed lacewing, Chrysopa oculata Say, which is released from thousands of microscopic dermal glands on the abdominal sterna. Iridodial-baited traps attract $C$. oculata and other Chrysopa spp. males into traps, while females come to the vicinity of, but do not usually enter traps. Despite their healthy appearance and normal fertility, laboratory-reared C. oculata males do not produce iridodial. Surprisingly, goldeneyed lacewing males caught alive in iridodial-baited traps attempt to eat the lure and, in Asia, males of other Chrysopa species reportedly eat the native plant, Actinidia polygama (Siebold \& Zucc.) Maxim. (Actinidiaceae) to obtain the monoterpenoid, neomatatabiol. These observations suggest that Chrysopa males must sequester exogenous natural iridoids in order to produce iridodial; we investigated this phenomenon in laboratory feeding studies. Lacewing adult males fed various monoterpenes reduced carbonyls to alcohols and saturated double bonds, but did not convert these compounds to iridodial. Only males fed the common aphid sex pheromone component, $(1 R, 4 \mathrm{a} S, 7 S, 7 \mathrm{a} R)$ nepetalactol, produced $(1 R, 2 S, 5 R, 8 R)$-iridodial. Furthermore, although $C$. oculata males fed the second common aphid sex pheromone component, $(4 \mathrm{aS}, 7 \mathrm{~S}, 7 \mathrm{a} R)$-nepetalactone, did not produce iridodial, they did convert $\sim 75 \%$ of this compound to the corresponding dihydronepetalactone, and wild C. oculata males collected in early spring contained traces of this dihydronepetalactone. These findings are consistent with the hypothesis that Chrysopa males feed on oviparae (the late-season pheromone producing stage of aphids) to obtain nepetalactol as a precursor to iridodial. In the spring, however, wild C. oculata males produce less iridodial than do males collected later in the season. Therefore, we further hypothesize that Asian Chrysopa eat A. polygama to obtain iridoid precursors in order to make their pheromone, and that other iridoid-producing plants elsewhere in the world must be similarly usurped by male Chrysopa species to sequester pheromone precursors. 


\section{Pharmacophagy in green lacewings (Neuroptera: Chrysopidae: Chrysopa spp.)?}

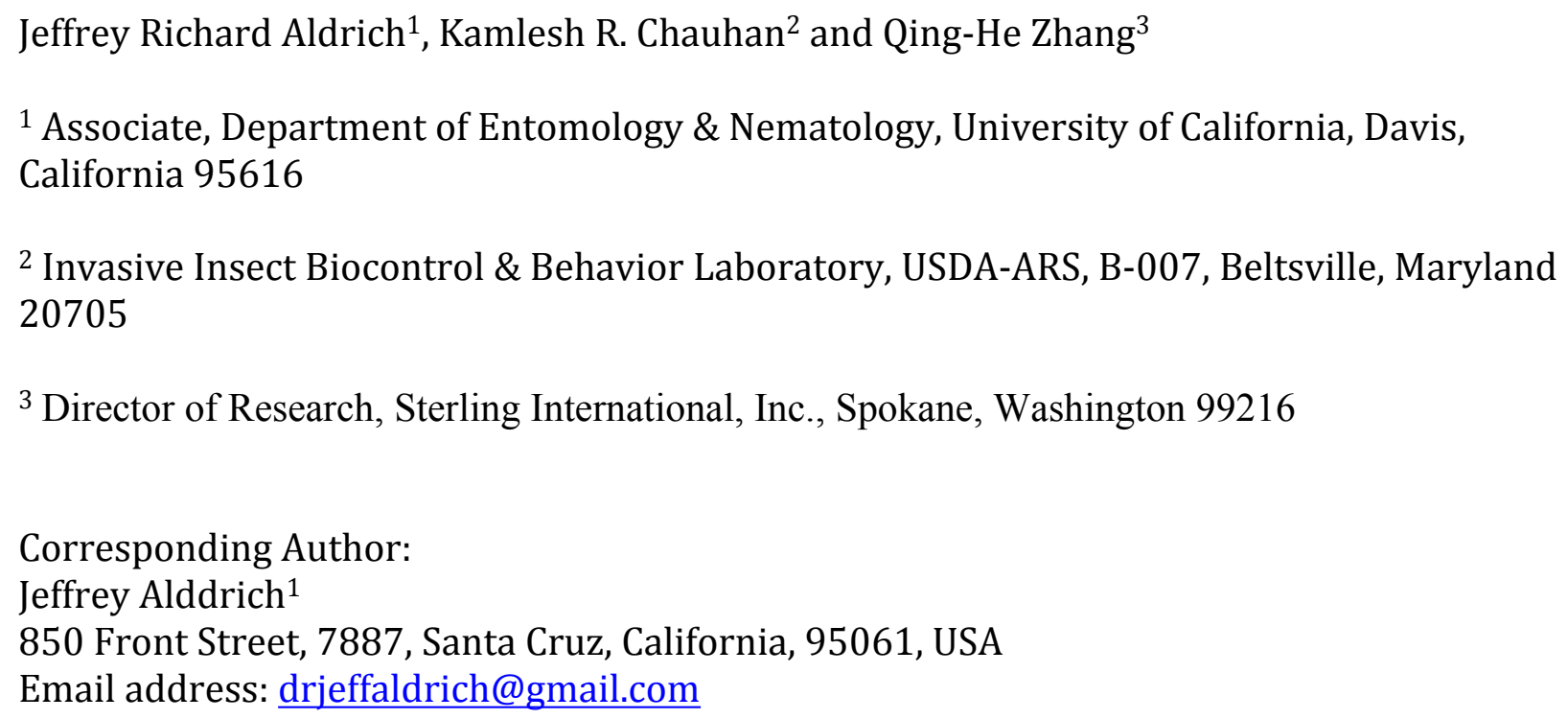




\section{ABSTRACT}

39 Green lacewings (Neuroptera: Chrysopidae) are voracious predators of aphids and other small, soft-bodied insects and mites. Earlier, we identified $(1 R, 2 S, 5 R, 8 R)$-iridodial from wild males of

41 the goldeneyed lacewing, Chrysopa oculata Say, which is released from thousands of microscopic dermal glands on the abdominal sterna. Iridodial-baited traps attract $C$. oculata and other Chrysopa spp. males into traps, while females come to the vicinity of, but do not usually enter traps. Despite their healthy appearance and normal fertility, laboratory-reared C. oculata males do not produce iridodial. Surprisingly, goldeneyed lacewing males caught alive in iridodial-baited traps attempt to eat the lure and, in Asia, males of other Chrysopa species reportedly eat the native plant, Actinidia polygama (Siebold \& Zucc.) Maxim. (Actinidiaceae) to obtain the monoterpenoid, neomatatabiol. These observations suggest that Chrysopa males must sequester exogenous natural iridoids in order to produce iridodial; we investigated this phenomenon in laboratory feeding studies. Lacewing adult males fed various monoterpenes reduced carbonyls to alcohols and saturated double bonds, but did not convert these compounds to iridodial. Only males fed the common aphid sex pheromone component, $(1 R, 4 \mathrm{a} S, 7 S, 7 \mathrm{a} R)$ nepetalactol, produced $(1 R, 2 S, 5 R, 8 R)$-iridodial. Furthermore, although $C$. oculata males fed the second common aphid sex pheromone component, $(4 \mathrm{a} S, 7 S, 7 \mathrm{a} R)$-nepetalactone, did not produce iridodial, they did convert $\sim 75 \%$ of this compound to the corresponding dihydronepetalactone, and wild C. oculata males collected in early spring contained traces of this dihydronepetalactone. These findings are consistent with the hypothesis that Chrysopa males feed on oviparae (the lateseason pheromone producing stage of aphids) to obtain nepetalactol as a precursor to iridodial. In the spring, however, wild C. oculata males produce less iridodial than do males collected later in the season. Therefore, we further hypothesize that Asian Chrysopa eat A. polygama to obtain 
61 iridoid precursors in order to make their pheromone, and that other iridoid-producing plants

62 elsewhere in the world must be similarly usurped by male Chrysopa species to sequester

63 pheromone precursors.

65 INTRODUCTION

66 With $\sim 6000$ living species, Neuroptera is one of the smaller orders of insects (Winterton et al.

67 2010), but most larval neuropterans are predacious, often in agricultural systems, lending added

68 importance to this group (Tauber et al. 2009). Green lacewings (Chrysopidae) are the most

69 agriculturally important of the neuropterans because their larvae are generalist predators that

70 actively hunt for aphids, mites, whiteflies, caterpillars, and other small, soft-bodied prey that are

71 common pests on horticultural plants, and in field and tree crops (McEwen et al. 2007). While

72 most chrysopids are also predacious as adults, species in the genus Chrysoperla feed on nectar

73 and pollen, a characteristic that led to development of artificial diets and mechanized mass

74 rearing of some species (McEwen et al. 2007; Nordlund et al. 2001). All stages of Chrysoperla

75 are commercially available for augmentative biological pest control in field and greenhouse

crops (Pappas et al. 2011). In addition, based on volatiles associated with their pollen and nectar

77 consumption, lures for Chrysoperla species have been developed to attract wild adults to pest infestations, and to overwintering and egg-laying sites (Koczor et al. 2014; Koczor et al. 2010;

79 Tóth et al. 2009; Wade et al. 2008).

Many other lacewings whose adults are predacious are naturally important in agricultural

81 systems, most notably Chrysopa species, but efforts to develop artificial diets or lures for these

82 species have been largely unsuccessful (McEwen et al. 2007). Pheromones are potentially useful

83 for attracting generalist predators for augmentative and conservation biological control (Aldrich 
84 1999), and there is ample morphological evidence that in many lacewing species males possess

85 exocrine glands likely to produce aggregation pheromones (Aldrich and Zhang 2016; Güsten 1996). Based upon the meticulous illustrations of male-specific dermal glands in Chrysopa

87 (Principi 1949; Principi 1954), we identified the first attractant pheromone for lacewings (Zhang et al. 2004). Field-collected males of the goldeneyed lacewing, Chrysopa oculata Say, release $(1 R, 2 S, 5 R, 8 R)$-iridodial with comparable amounts of nonanal, nonanol and nonanoic acid (Zhang et al. 2004). Moreover, iridodial-baited traps attracted C. oculata males into traps and females to the vicinity of baited traps (Chauhan et al. 2007). Adult $C$. oculata females lack the dermal glands associated with iridodial production, and do not produce iridodial (Zhang et al. 2004). Subsequently, we found that the same iridodial stereoisomer as identified from wild C. oculata males also attracted adults of C. nigricornis Burmeister in the western U.S. (Zhang et al. 2006a), and C. septempunctata Wesmael in China (Zhang et al. 2006b). The discovery that iridodial powerfully attracted at least three different Chrysopa spp., and that the stereochemically correct isomer of iridodial can be prepared using catnip essential oil as starting material (Chauhan et al. 2004), encouraged us to pursue pheromone identifications for other lacewings whose males reportedly possess dermal glands similar to those of Chrysopa males; i.e. species in the genera Plesiochrysa, Ceratochrysa, Nineta, a (C) seudomallada (= Anisochrysa) (Aldrich and Zhang 2016). But, our plan to pursue pheromone research on some of

102 these chrysopids by rearing them in quarantine was thwarted by the discovery of one us (JRA)

103 that, despite their healthy appearance, normal fertility and usual amounts of $\mathrm{C}_{9}$ compounds,

104 laboratory-reared C. oculata males produced no iridodial. Furthermore, an observation by

105 another of us (Q-HZ) that C. nigricornis males caught alive in traps baited with iridodial 106 attempted to eat the lure (unpublished observation), combined with previous reports of Chrysopa 
107 septempunctata eating the plant known as silver leaf, Actinidia polygama (Siebold \& Zucc.)

108 Maxim (Actinidiaceae; native to Asia) to obtain the monoterpene iridoids (neomatatabiols)

109 (Supplemental Figure 1, compounds 5 and 6) (Hyeon et al. 1968), suggested that Chrysopa

110 males must obtain certain unknown precursors from their diet in order to produce their

111 pheromone.

112 The objectives of the present study were to 1) devise techniques to feed suspected

113 pheromone precursors to $C$. oculata males and, 2) discover what precursor compound(s) elicit

114 production of iridodial by C. oculata males.

115

116 MATERIALS AND METHODS

117 Lacewing collection and rearing

118 Adults of C. oculata for the laboratory colony were collected in May of 2008 by sweep net from

119 wild herbaceous vegetation bordering deciduous trees at the Beltsville Agricultural Research

120 Center, Prince George's County, Maryland, USA. Quart wide-mouth Mason ${ }^{\circledR}$ canning jars

121 (Mason Highland Brands, LLC, Hyrum, UT) were used to maintain the adult insects. The jars

122 were positioned horizontally, and nylon organdy cloth (G Street Fabrics, Rockville, MD) was

123 held in place by the screw-top rim used to seal the jars. Jars were provisioned with live

124 parthenogenic pea aphids [Homoptera: Aphidae: Acyrthosiphon pisum (Harris)] (supplied by Dr.

125 John Reese, Kansas State University), eggs of the Angoumois grain moth (Gelechiidae: Sitotroga

126 cerealella (Oliver); Kunafin "the Insectary", Quemado, TX), and a 10\% honey solution. A 5 x 12

$127 \mathrm{~cm}$ piece of cardboard was used as a feeding platform. Honey solution was provided in a shell

128 vial (4 ml, 15 x 45 mm; Fisher Scientific, Pittsburgh, PA) with a loose-fitting foam stopper

129 secured at one end of the cardboard with a rubber band. An adhesive strip of a Post-it ${ }^{\circledR}$ paper (50 
130 x $40 \mathrm{~mm}$; 3M, St. Paul, MN) was gently applied to the Sitotroga eggs, and the paper was glued

131 (UHUstic $^{\circledR}$, UHU GmbH \& Co., Bühl, Germany) to the other end of the cardboard with the band

132 of moth eggs exposed. The cardboard feeding platform thus prepared was inserted into the

133 bottom of the horizontal jar, and live pea aphid clones (up to several hundred) were added to the

134 cage. Ten to twenty adults could be kept per jar, adding fresh aphids and moth eggs every other

135 day or so, and adding fresh honey solution as needed. In jars used as mating cages (5-10

136 pairs/jar), a piece of light blue colored paper (providing a color contrast to the green eggs that are

137 laid singly on stalks) was inserted inside the length of the jar as an oviposition substrate.

138 Servicing of these jars was accomplished by working in a cage $(30 \times 30 \times 60 \mathrm{~cm}$; BioQuip

139 Products, Rancho Dominguez, CA, USA) open at one end, and illuminated at the top of the other

140 end by a fluorescent light. Adults from mating jars were moved to new jars weekly, the food

141 platform was removed from the jar with freshly laid lacewing eggs, and the eggs that had been

142 laid were allowed to hatch. Using a camel-hair brush, two first-instar larvae were transferred to

143 each plastic cup (3/4 oz., snap-on lids; Solo Cup Company, Urbana, IL) with a layer of Sitotroga

144 eggs in the bottom. Cups provisioned with only Sitotroga eggs were usually sufficient for both

145 larvae to complete all 3 instars and pupate; more than two larvae per cup usually resulted in

146 cannibalism. Lacewing pupae were transferred to the bottom compartment of mosquito breeders

147 (BioQuip Products) and, upon emergence, the adults were removed from the top compartment.

148 The colony was maintained in an environmental chamber set at $25{ }^{\circ} \mathrm{C}, 72 \%$ relative humidity,

149 and 16:8 h (L:D) photoperiod. Some C. oculata males were reared as just described, plus with

150 access to foliage of Nepeta cataria (Catnip) (Mountain Valley Seed Inc., Salt Lake City, UT; lot

151 \#G2217); some had their antennae removed (antennectomized) 1-5 days after emergence; and

152 some larvae were reared as above, and fed pea aphid clones. 
154 larvae have piercing/sucking mouthparts (Tauber et al. 2009); therefore, some larvae were reared

155 with methylene blue dye added to the honey solution to verify that larvae ingested materials from

156 the honey water bottles, as did adults. Adult males from these treatments were subsequently

157 chemically sampled and analyzed as described below.

\section{Scanning election microscopy}

160 Live wild $C$. oculata males were anesthetized with $\mathrm{CO}_{2}$, mounted on copper specimen holders

$161(16 \times 29 \times 1.5 \mathrm{~mm}$ thick $)$ with cryoadhesive, and immersed in liquid $\mathrm{N}_{2}$. The frozen specimens

162 were transferred to an Oxford CT1500 HF cryo-preparation system, and examined using a low

163 temperature scanning electron microscope (LTSEM; Hitachi S-4100) operated at $2.0 \mathrm{kV}$ (Erbe et

164 al. 2003). Micrographs were recorded on Polaroid Type 55 P/N film.

166 Chemical standards

$167(Z, E)$-Nepetalactone $[=(4 \mathrm{a} S, 7 S, 7 \mathrm{a} R)$-nepetalactone $]$ was prepared from catnip oil;

168 dihydronepetalactone was from hydrogenation of the lactone; $(Z, E)$-nepetalactol $[=$

$169(1 R, 4 \mathrm{a} S, 7 S, 7 \mathrm{a} R)$-nepetalactol] was from $\mathrm{NaBH}_{4}$ reduction of the lactone; and $1 R, 2 S, 5 R, 8 R$ -

170 iridodial was derived from the $(Z, E)$-nepetalactone as previously described (Chauhan et al.

171 2004). Geranyl and farnesyl pyrophosphates were from Sigma-Aldrich (Saint Louis, MO), as

172 were the following volatile standards ( $\geq 95 \%)$ : geraniol, citronellol, citronellal, linalool, citral, 6-

173 methyl-5-hepten-2-one, 8-hydroxycitronellol, and 8-hydroxycitronellal. (Z)-3-Octen-1-ol was

174 from Bedoukian Research, Inc. (Danbury, CT). 
176 Chemical feeding, extraction of dermal glands, and chemical analysis

177 Chemical standards were individually fed to adult laboratory-reared C. oculata males at $1 \mu \mathrm{g} / \mu \mathrm{l}$

178 in the $5 \%$ aqueous honey solution for ca. 4 days prior to analysis. For extraction, C. oculata adult

179 males were anesthetized with $\mathrm{CO}_{2}$, eviscerated under tap water, the abdominal cuticle (segments

180 1-8) was removed with microscissors, cleaned of fat under water with micro-forceps, then

181 removed from the water, and dried briefly with tissue paper. Cuticle from a single male was

182 extracted in 10-15 $\mu \mathrm{l}$ of $\mathrm{CH}_{2} \mathrm{Cl}_{2}$ ( $\geq 99.9 \%$; Sigma-Aldrich) in a Waters Alliance Total Recovery

$183 \mathrm{Vial}^{\circledR}$ (deactivated, 12x32 mm; Taunton, MA/USA) or the minimum amount of solvent

184 necessary to submerge the cuticles for pooled samples of several males (ca. 50-150 $\mu$ l) (Zhang et

185 al. 2004). Wild males collected by sweep net, Beltsville MD, May - June, 2008 and 2009, were

186 dissected in like manner the same day as collected.

187 Gas chromatography (GC) and coinjections were performed in splitless mode using an

188 HP 6890 GC equipped with a DB-5 column $(0.25 \mu \mathrm{m}$ film thickness, $30 \mathrm{~m}$ x $0.32 \mathrm{~mm}$ ID; J \& W

189 Scientific, Folsom, CA). Helium was used as the carrier gas, programming from $50{ }^{\circ} \mathrm{C} / 2 \mathrm{~min}$, to

$190250{ }^{\circ} \mathrm{C}$ at $10 \circ \mathrm{C} / \mathrm{min}$, then held for $10 \mathrm{~min}$. GC-mass spectrometry (GC-MS) analyses were

191 performed in splitless mode with an electron impact ionization (EI) of $70 \mathrm{eV}$ with an Agilent

192 Technologies 5973 mass selective detector interfaced with 6890N GC system equipped with

193 either an HP-5MS $(30 \mathrm{~m} \times 0.25 \mathrm{~mm}$ i.d. $\times 0.25 \mu \mathrm{m}$ film $)$ column programmed from $50 \circ \mathrm{C} / 2 \mathrm{~min}$,

194 rising to $230^{\circ} \mathrm{C}$ at $15^{\circ} \mathrm{C} / \mathrm{min}$, then held for $15 \mathrm{~min}$, or using a DB-WaxETR column $(0.25 \mu \mathrm{m}$

195 film thickness, $30 \mathrm{~m} \times 0.25 \mathrm{~mm}$ ID; J \&W Scientific, Folsom, CA) programmed at 50॰C/2 min,

196 rising to $230^{\circ} \mathrm{C}$ at $15^{\circ} \mathrm{C} / \mathrm{min}$, then held for $15 \mathrm{~min}$.

197

198 RESULTS 
199 Chrysopa adults are ca. $1.5-2 \mathrm{~cm}$ in length, and males are readily attracted to and captured in 200 sticky traps (Fig. 1) (Zhang et al. 2006b). In adult C. oculata males the dermal glands (Güsten 201 1996) are elliptical $(\sim 12 \times 7.5 \mu \mathrm{m})$ with a central slit (Fig. 2), and occur on the 3rd-8th

202 abdominal sternites ( $~ 800,2100,2500,2500,2300$ and 1500, respectively); corresponding 203 dermal glands are absent in females (Zhang et al. 2004).

204 Analyses of C. oculata revealed that nonanal and nonanol were abundant in extracts of 205 the abdominal sternites of males regardless of whether they were collected in the wild or reared 206 in the laboratory; however, iridodial was absent in extracts of laboratory-reared C. oculata males 207 (Fig. 3A and B; Table 1). Rearing C. oculata males in isolation from conspecific males did not 208 result in production of iridodial (Table 1), and removing the antennae of C. oculata males had no 209 affect on production of iridodial (Supplemental Figure 2). Access of C. oculata males to Nepeta 210 cataria (catnip) foliage in the laboratory did result in a detectable level of iridodial

211 (Supplemental Figure 3); however, this level was far below that seen for wild C. oculata males

212 (Table 1). In wild males collected by sweep netting foliage in early spring (i.e. not from

213 iridodial-baited traps) the mean iridodial percentage relative to the abundances of nonanal and

214 nonanol was $14.30 \%( \pm$ SEM $=3.72)($ Table 1$)$. Analysis of one male caught in an iridodial-

215 baited trap (14 May 208Beltsville, MD) to which the captured males had access to the lure,

216 showed that this male produced much more iridodial $(40.71 \%)$ than the normal mean abundance

217 of iridodial in wild C. oculata males (Table 1). (Z)-3-Octen-1-ol was used as an internal standard 218 to quantitate pheromone production per wild C. oculata males collected in May 2008; extracts of 219 single males contained $20.42 \pm 6.88 \mathrm{ng}$ iridodial/male (mean $\pm \mathrm{SEM} ; \mathrm{N}=8$ ) (Supplemental Data, 220 Iridodial Quantitation).

221 Feeding naturally common monoterpene alcohols and aldehydes to C. oculata males did 
222 not stimulate production of iridodial (Table 2, experiment numbers 1-8). However, this series of

223 feeding trials did reveal that males evidently possess reductase and saturase enzymes capable of

224 reducing aldehydes to alcohols, and of saturating double bonds in these molecules. These

225 reactions were essentially unidirectional; for example, geranial was completely converted to

226 geraniol (Table 2, experiment number 2), whereas geraniol was only slightly isomerized to nerol

227 but aldehydes were not produced (Table 2, experiment number 6). Furthermore, the abundances

228 of $\mathrm{C}_{9}$ compounds were not affected; nonanal, nonanol and nonanoic acid occurred in ratios

229 within their ranges for wild-caught males for all experiments shown in Table 2.

230 Feeding male goldeneyed lacewings the common aphid pheromone components,

$231(4 \mathrm{a} S, 7 S, 7 \mathrm{a} R)$-nepetalactone and $(1 R, 4 \mathrm{a} S, 7 S, 7 \mathrm{a} R)$-nepetalactol, produced positive results. While

232 feeding nepetalactone did not result in production of iridodial, about $75 \%$ of this lactone was

233 converted to the dihydronepetalactone (Table 2, experiment number 9). Furthermore,

234 dihydronepetalactone was detected at low, but unequivocal levels in some samples from wild $C$.

235 oculata males (Supplemental Figures 4 and 5). Chrysopa oculata males fed (1R,4aS,7S,7aR)-

236 nepetalactol converted this compound to $(1 R, 2 S, 5 R, 8 R)$-iridodial $(82.7 \%$; Table 2, experiment

237 number 10; Fig. 3C), with two later eluting $168 \mathrm{MW}$ compounds accounting for $17.3 \%$ of the

238 other newly appearing components, as well as (Z)-4-tridecene from the defensive prothoracic

239 glands (Fig. 3C, compound c) (Aldrich et al. 2009). Two additional feeding experiments were

240 conducted as for experiment 10 (Table 2); one of these experiments using the same GC-MS

241 conditions $(\mathrm{N}=9$ males $)$ showed $54.90 \%$ conversion to $(1 R, 2 S, 5 R, 8 R)$-iridodial with the two

242 later eluting $168 \mathrm{MW}$ components totaling $40.10 \%$, and the second experiment $(\mathrm{N}=4$ males $)$

243 analyzed using a 30m HP-5 column resulted in $100 \%$ conversion to $(1 R, 2 S, 5 R, 8 R)$-iridodial

244 (Supplemental Data, Table 2, \#10a \& b). 
Finally, feeding experiments conducted with C. oculata larvae failed to stimulate more

246 than trace levels of iridodial in the resulting male adults. Providing pea aphid clones to larvae

247 during rearing yielded at most only traces of iridodial in the ensuing adult males (Supplemental

248 Data, Larvae Fed Aphids). While Chrysopa oculata larvae provided with honey water solution

249 containing methylene blue turned decidedly blue, verifying this method as an appropriate means

250 to feed suspected pheromone precursors to larvae, feeding geranyl or farnesyl pyrophosphates

251 did not stimulate detectable production of iridodial in the ensuing adult males (Supplemental

252 Data, Larvae Fed Terpene Phosphates). Feeding C. oculata larvae with (1R,4aS,7S,7aR)-

253 nepetalactol, which in laboratory-reared adult males resulted in wild-type levels of

$254(1 R, 2 S, 5 R, 8 R)$-iridodial, produced trace levels of iridodial far lower than wild-type levels of the

255 pheromone (Supplemental Data, Larvae Fed Nepetalactol).

256

257 DISCUSSION

258 Coincidence of male-specific dermal glands with extraction of $(1 R, 2 S, 5 R, 8 R)$-iridodial from the $2593^{\text {rd }}-8^{\text {th }}$ abdominal sternites strongly implicates these glands as the pheromone source (Zhang et

260 al. 2004). Surprisingly, only males are caught in traps baited with this iridodial (Zhang et al.

261 2004; Zhang et al. 2006a; Zhang et al. 2006b); however, females are drawn to the vicinity of, but

262 seldom enter, iridodial-baited traps (Chauhan et al. 2007). Presumably, females stop short of

263 entering traps because the close-range substrate-borne vibrational signals to which females are

264 ultimately attracted (Henry 1982) are disrupted by trapping males. The $\mathrm{C}_{9}$ compounds are

265 unattractive to $C$. oculata, quantitatively much less variable than iridodial, and inhibitory to

266 iridodial attraction, suggesting these compounds play a role independent from that of iridodial

267 (Zhang et al. 2004). 
269 fertile matings when fed only sugar and water, whereas females needed to feed on pea aphid

270 clones in order to mate and produce fertile eggs (Tauber and Tauber 1973). Our results support

271 these finding, but also make it clear that $C$. oculata males are unable to make pheromone on this

272 feeding regimen. Iridodial production in C. oculata males was not stimulated by 1)

273 antennectomy of sexually mature $C$. oculata males, which in some group-reared insects

274 stimulates pheromone production (e.g. Dickens et al. 2002); 2) providing access to catnip plants,

275 Nepeta cataria, containing the nepetalactone aphid pheromone component (Pickett et al. 2013)

276 or; 3) rearing C. oculata males in isolation, which in some insects is required for maximal

277 pheromone production (Ho et al. 2005; Khrimian et al. 2014).

278 Cyclopentanoid natural products based on an iridoid structure are widespread in plants

279 and insects (Hilgraf et al. 2012; Lorenz et al. 1993), and incorporation of $\left[{ }^{14} \mathrm{C}\right]$ mevalonolactone

280 by the stick insect, Anisomorpha buprestoides (Stoll) (Phasmatodea: Pseudophasmatidae), and

281 the catnip plant (N. cataria) demonstrated that biosynthesis of their respective iridoids,

282 anisomorphal and nepetalactone, proceed via parallel terpene pathways from acyclic precursors,

283 particularly geraniol (Meinwald et al. 1966). Larvae of leaf beetles (Coleoptera: Chrysomelidae)

284 from four different genera showed that biosynthesis of the iridoid defensive compound,

285 chrysomelidial, proceeds from geraniol via an $\omega$-oxidation sequence to 8-hydroxygeraniol, with

286 the eventual cyclization of 8-oxocitral to form the characteristic iridoid cyclopentanoid ring

287 structure (Hilgraf et al. 2012; Lorenz et al. 1993; Veith et al. 1994). Certain rove beetles

288 (Coleoptera: Staphylinidae: Philonthus spp.) also produce defensive secretions containing

289 iridoids (e.g. plagiodial), but unlike enzymes from iridoid-producing leaf beetle larvae, the

290 Philonthus enzyme is able to oxidize and cyclize saturated substrates such as citronellol (Weibel 
291 et al. 2001). In plants, including a catnip species (N. racemosa) (Hallahan et al. 1995), the

292 cyclization reactions to iridoids proceed via 10-hydroxygeraniol and 10-oxogeranial rather than

293 8-hydroxygeraniol/al (Geu-Flores et al. 2012). Furthermore, Hilgraf et al. (2012) stressed that

294 there are still many open questions concerning the biosynthesis of iridoids, particularly

295 "saturated" iridoids such as iridodial.

296 In contrast to other iridoid-producing insects and plants whose biosynthetic pathways

297 have been investigated, Chrysopa males are evidently incapable of cyclizing geraniol or other

298 acyclic analogs to form the cyclopentanoid ring structure characteristic of iridoid compounds.

299 Thus, feeding acyclic monoterpene alcohols and aldehydes to C. oculata males did not stimulate

300 production of iridodial. However, our feeding trials revealed that $C$. oculata males are capable of

301 reducing aldehydes to alcohols and of saturating double bonds. Moreover, males fed the common

302 aphid pheromone component, $(4 \mathrm{a} S, 7 S, 7 \mathrm{a} R)$-nepetalactone, converted $\sim 75 \%$ to

303 dihydronepetalactone, and males fed the other common aphid pheromone component,

$304(1 \mathrm{R}, 4 \mathrm{aS}, 7 \mathrm{~S}, 7 \mathrm{aR})$-nepetalactol, converted this bicyclic iridoid to $(1 R, 2 S, 5 R, 8 R)$-iridodial.

305 Interestingly, analyses of wild C. oculata males collected in May often revealed the presence of

306 dihydronepetalactone.

307 One interpretation of these data is that C. oculata males must eat aphid oviparae to obtain

308 nepetalactol in order to make their pheromone. Indeed, in northern California the peak late-

309 season attraction of green lacewings to nepetalactol (nepetalactone is unattractive) occurs at least

310 a month earlier than the peak in aphid oviparae (Symmes 2012), consistent with the hypothesis

311 that Chrysopa males feed on oviparae to obtain nepetalactol as a precursor for iridodial. These

312 dynamics indicate there is sufficient time for Chrysopa males to feed on oviparae, produce

313 iridodial, mate, and have conspecific females' offspring reach the prepupal overwintering stage 
314 (Uddin et al. 2005). However, adult males from laboratory-reared C. oculata larvae fed

315 nepetalactol still failed to produce wild-type levels $\oplus$ idodial even though wild C. oculata

316 males collected early in the spring produce less iridodial than do males collected later in the

317 season (Zhang et al. 2004). Although some aphids produce oviparae under stressed conditions

318 in summer (Hardie 1985), it seems unlikely that these oviparae are a reliable or abundant enough

319 source to sustain Chrysopa male pheromone production. Therefore, we further hypothesize the

320 raison d'etre that Asian Chrysopa eat fruit and foliage of silver leaf (A. polygama) is to obtain

321 iridoid precursors necessary to make their pheromone; we believe that other iridoid-producing

322 plants (e.g. Hilgraf et al. 2012; Prota et al. 2014) elsewhere in the world must be similarly

323 usurped by male Chrysopa species to sequester iridoid pheromone precursors.

324 Contrary to Chrysoperla green lacewings whose adults are not predacious, Chrysopa spp.

325 lacewing adults are predacious (Tauber et al. 2009), and appear to exhibit pharmacophagy; that

326 is, they "search for certain secondary plant substances directly, take them up, and utilize them for

327 a specific purpose other than primary metabolism" (Boppré 1984). A prime example of

328 pharmacophagy are male Bactrocera fruit flies (Tephritidae) that feed on plants to obtain their

329 pheromone precursor, methyl eugenol (Tan and Nishida 2012). Indeed, males of certain

330 lacewings [i.e. Ankylopteryx exquisite (Nakahara) (Pai et al. 2004), and Mallada basalis

331 (Walker) (Oswald 2015; Suda and Cunningham 1970)] are also powerfully attracted to methyl

332 eugenol for unknown reasons (Tan and Nishida 2012). In addition, certain chrysomelid beetle

333 larvae discharge iridoid allomones that may be synthesized de novo, which is considered

334 ancestral, or produced via the more evolutionarily advanced mechanism, sequestration from

335 plants (Kunert et al. 2008). Increasingly, pharmacophagy is being recognized as a widespread

336 phenomenon in insects, and Wyatt (2014) has extended the concept of pharmacophagy to include 
337 molecules produced by bacteria that are used as pheromones, such as locust phase-change

338 pheromones produced by gut bacteria. If male Chrysopa spp. lacewings actually do seek out

339 aphid oviparae to obtain nepetalactol as a precursor to iridodial, and in this regard it should be

340 noted that only Chrysopa males are attracted to nepetalactol (Koczor et al. 2015), then the

341 concept of pharmacophagy must be further extended to include this type of predator/prey

342 interaction. Whether or not sequestration of iridodial precursors from oviparae and/or iridoid-

343 containing plants is truly the explanation for lack of pheromone in laboratory-reared Chrysopa

344 awaits further research.

\section{CONCLUSIONS}

347 Goldeneyed lacewing males, Chrysopa oculata (Neuroptera: Chrysopidae), produce

$348(1 R, 2 S, 5 R, 8 R)$-iridodial as an aggregation pheromone from specialized dermal glands on the

349 abdomen; however, seemingly normal laboratory-reared males of $C$. oculata do not produce

350 iridodial. Feeding studies with C. oculata showed that males of these predatory insects fed one of

351 the common aphid sex pheromone components, $(1 R, 4 \mathrm{a} S, 7 S, 7 \mathrm{a} R)$-nepetalactol, sequester this

352 compound and convert it to the stereochemically correct lacewing pheromone isomer of

353 iridodial. These data, combined with literature accounts of other Chrysopa species from the

354 Oriental region that feed on iridoid-producing plants, suggest these (and some other) lacewing

355 species must obtain precursors from aphid oviparae and/or certain plants containing iridoids in

356 order to make pheromone. The phenomenon, known as pharmacophagy, whereby an insect

357 searches for certain secondary plant substances and sequesters the chemicals for a specific

358 purpose other than primary metabolism, is widespread among phytophagous insects but, to our

359 knowledge, is unknown among lacewings or other predacious insects. Our findings, if verified, 
360 have significant implications for lacewing-based biological control of aphids and other small

361 arthropod pests.

362

363 ACKNOWLEDGEMENTS

364 The authors wish to dedicate this manuscript to the memory of Dr. Murray S. Blum (July 19,

3651929 - March 22, 2015), University of Georgia, Athens, who was a true pioneer of chemical

366 ecology and mentor to many of us in this field. On the occasion of her $100^{\text {th }}$ birthday this year,

367 we recognize the grande dame of neuropterists, Maria Matilde Principi, for her inspirational

368 work describing the pheromone glands of lacewings. We are also grateful to Professor Wilhelm

369 Boland (Department of Bioorganic Chemistry, Max Planck Institute for Chemical Ecology, Jena,

370 Germany) for helpful discussions. Dr. John Reese (Department of Entomology, Kansas State

371 University, Manhattan) provided live pea aphids weekly for the duration, which made this

372 research possible. Finally, one of us (JRA) thanks Mr. Ed Clark for his expert technical

373 assistance.

374

375 REFERENCES

376

377

Aldrich JR. 1999. Predators: Pheromones and kairomones. In: Hardie RJ, Minks AK, editors. Pheromones of Non-lepidopteran Insects Associated with Agricultural Plants. Wallingford, U. K.: CAB International Publishing. p 357-381.

379

380

381

382

383

384

385

386

387

Aldrich JR, Le TC, Zhang Q-H, Torres J, Winterton SL, Han B, Miller GL, Chauhan KR. 2009. Prothoracic gland semiochemicals of green lacewings (Neuroptera: Chrysopidae). J. Chem. Ecol. 35(10):1181-1187.

Aldrich JR, Zhang Q-H. 2016. Chemical ecology of Neuroptera. Annu. Rev. Entomol. 61:doi: 10.1146/annurev-ento-010715-023507.

Boppré M. 1984. Redefining "Pharmacophagy". J. Chem. Ecol. 10(7):1151-1154.

Chauhan KR, Levi V, Zhang Q-H, Aldrich JR. 2007. Female goldeneyed lacewings

(Neuroptera: Chrysopidae: Chrysopa oculata) approach but seldom enter traps 
388

389

390

391

392

393

394

395

396

397

398

399

400

401

402

403

404

405

406

407

408

409

410

411

412

413

414

415

416

417

418

419

420

421

422

423

424

425

426

427

428

429

430

431

432

433

baited with the male-produced compound, iridodial. J. Econ. Entomol. 100(6):17511755.

Chauhan KR, Zhang Q-H, Aldrich JR. 2004. Iridodials: Enantiospecific synthesis and stereochemical assignment of the pheromone for the goldeneyed lacewing, Chrysopa oculata. Tetrahedron Lett. 45(17):3339-3340.

Dickens JC, Oliver JE, Hollister B, Davis JC, Klun JA. 2002. Breaking a paradigm: maleproduced aggregation pheromone for the Colorado potato beetle. J. Exp. Biol. 205(13):1925-1933.

Erbe EF, Rango A, Foster J, Josberger E, Pooley C, Wergin WP. 2003. Collecting, shipping, storing and imaging snow crystals and ice grains with low temperature scanning electron microscopy. Microsc. Res. Tech. 62:19-32.

Geu-Flores F, Sherden NH, Courdavault V, Burlat V, Glenn WS, Wu C, Nims E, Cui Y, Connor SE. 2012. An alternative route to cyclic terpenes by reductive cyclization in iridoid biosynthesis. Nature 492(7427):138-142.

Güsten R. A review of epidermal glands in the order Neuroptera (Insecta). In: Canard M, Aspöck H, Mansell MW, editors; 1996; Cairo, Egypt, 1994. Privately printed, Toulouse, France. p 129-146.

Hallahan DL, West JM, Wallsgrove RM, Smiley DW, Dawson GW, Pickett JA, Hamilton JG. 1995. Purification and characterization of an acyclic monoterpene primary alcohol: NADP+ oxidoreductase from catmint (Nepeta racemosa). Arch. Biochem. Biophysics 318(1):105-112.

Hardie J. 1985. Starvation-induced oviparae in the black bean aphid, Aphis fabae. Entomol. Exp. \& Appl. 38(3):287-289.

Henry CS. 1982. Reproductive and calling behavior in two closely related sympatric lacewing species, Chrysopa oculata and Chrysopa chi (Neuroptera: Chrysopidae). Proc. Entomol. Soc. Wash. 84(1):191-203.

Hilgraf R, Zimmermann N, Lehmann L, Tröger A, Francke W. 2012. Stereoselective synthesis of trans-fused iridoid lactones and their identification in the parasitoid wasp Alloxysta victrix, Part II: Iridomyrmecins. Beilstein J. Org. Chem. 8:1256-1264.

Ho H-Y, Hsu Y-C, Chuang Y-C, Chow Y-S. 2005. Effect of rearing conditions on production of sternal gland secretion, and identification of minor components in the sternal gland secretion of the predatory stink bug Eocanthecona furcellata. J. Chem. Ecol. 31(1):29-37.

Hyeon SB, Isoe S, Sakan T. 1968. The structure of neomatatabiol, the potent attractant for Chrysopa from Actinidia polygama. Tetrahedron Lett. 51:5325-5326.

Khrimian A, Zhang A, Weber DC, Ho H-Y, Aldrich JR, Vermillion KE, Siegler MA, Shirali S, Guzman F, Leskey TC. 2014. Discovery of the aggregation pheromone of the brown marmorated stink bug (Halyomorpha halys) through the creation of stereoisomeric libraries of 1-bisabolen-3-ols. J. Nat. Prod. 77(7):1708-1717.

Koczor S, Knudsen GK, Hatleli L, Szentkirályi F, Tóth M. 2014. Manipulation of oviposition and overwintering site choice of common green lacewings with synthetic lure (Neuroptera: Chrysopidae). J. Appl. Entomol. 139(3):201-206.

Koczor S, Szentkirályi F, Birkett MA, Pickett JA, Voigt E, Tóth M. 2010. Attraction of Chrysoperla carnea complex and Chrysopa spp. lacewings (Neuroptera: Chrysopidae) to aphid sex pheromone components and a synthetic blend of floral compounds in Hungary. Pest Manage. Sci. 66(12):1374-1379. 
434 Koczor S, Szentkirályi F, Pickett JA, BIrkett MA, Tóth M. 2015. Aphid sex phermone

435

436

437

438

439

440

441

442

443

444

445

446

447

448

449

450

451

452

453

454

455

456

457

458

459

460

461

462

463

464

465

466

467

468

469

470

471

472

473

474

475

476

477 compounds interfere with attraction of common green lacewings (Neuroptera: Chrysopidae) to floral bait J. Chem. Ecol. 41(6):550-556.

Kunert M, Søe A, Bartram S, Discher S, Tolzin-Banasch K, Nie L, David A, Pasteels J, Boland W. 2008. De novo biosynthesis versus sequestration: a network of transport systems supports in iridoid producing leaf beetle larvae both modes of defense. Insect Biochem. Mol. Biol. 38(10):895-904.

Lorenz M, Boland W, Dettner K. 1993. Biosynthesis of iridodials in the defense glands of beetle larvae (Chrysomelinae). Angew. Chem. Int. Ed. Engl. 32(6):912-914.

McEwen PK, New TR, Whittington AE. 2007. Lacewings in the crop environment: Cambridge University Press.

Meinwald J, Happ GM, Labows J, Eisner T. 1966. Cyclopentanoid terpene biosynthesis in a phasmid insect and in catmint. Science 151(3706):79-80.

Nordlund D, Cohen A, Smith R, McEwen P, New T, Whittington A. 2001. Mass-rearing, release techniques, and augmentation. In: P. K. McEwen TRN, A. E. Whittington, editor. Lacewing in the Crop Environment: Cambridge University Press: Cambridge. p 303-319.

Oswald JD. 2015. Lacewing Digital Library. Lacewing Digital Library module. http://lacewing.tamu.edu/ Accessed on 30 July 2015.

Pai KF, Chen CJ, Yang JT, Chen CC. 2004. Ankylopteryx exquisite attracted to methyl eugenol. Plant Prot. Bull. 46:93-97.

Pappas ML, Broufas GD, Koveos DS. 2011. Chrysopid predators and their role in biological control. J. Entomol. 8(3):301-326.

Pickett JA, Allemann RK, Birkett MA. 2013. The semiochemistry of aphids. Nat. Prod. Rep. 30(10):1277-1283.

Principi MM. 1949. Morfologia, anatomia e funzionamento degli apparati genitali nel gen. Chrysopa Leach (Chrysopa septempunctata Wesm. e C. formosa Brauer). Boll. Ist. Ent. Univ. Bologna 17:316-362.

Principi MM. 1954. Singolari strutture glandolari nel torace e nell'addome dei maschi di alcune specie di neurotteri crisopidi. Atti Accad. Naz. Lincei Rc., Cl. Sci. 16:678-685.

Prota N, Mumm R, Bouwmeester HJ, Jongsma MA. 2014. Comparison of the chemical composition of three species of smartweed (genus Persicaria) with a focus on drimane sesquiterpenoids. Phytochem. 108:129-136.

Suda DY, Cunningham RT. 1970. Chrysopa basalis captured in plastic traps containing methyl eugenol. J. Econ. Entomol. 63:1076.

Symmes EJ. 2012. Improving Management of Mealy Plum Aphids (Hyalopterus pruni) and Leaf-Curl Plum Aphids (Brachycaudus helichrysi) in Dried Plum Orchards Using Sex Pheromones. ProQuest LLC, Ann Arbor, MI: Ph D thesis, Univ. Calif., Davis. 172 p.

Tan KH, Nishida R. 2012. Methyl eugenol: its occurrence, distribution, and role in nature, especially in relation to insect behavior and pollination. J. Insect Sci. 12(1):56.

Tauber CA, Tauber MJ, Albuquerque GS. 2009. Neuroptera: (Lacewings, Antlions). In: Resh VH, Cardé RT, editors. Encyclopedia of Insects: Academic Press. p 695-707.

Tauber MJ, Tauber CA. 1973. Dietary requirements for mating in Chrysopa oculata (Neuroptera: Chrysopidae). Can. Entomol. 105:79-82. 
478

479

480

481

482

483

484

485

486

487

488

489

490

491

492

493

494

495

496

497

498

499

500

501

502

503

504

505

506

507
Tóth M, Szentkiráslyi F, Vuts JD, Letardi A, Tabilio MR, Jaastad G, Knudsen GK. 2009. Optimization of a phenylacetaldehyde-based attractant for common green lacewings (Chrysoperla carnea s.l.). J. Chem. Ecol. 35(4):449-458.

Uddin J, Holliday N, MacKay P. 2005. Rearing lacewings, Chrysoperla carnea and Chrysopa oculata (Neuroptera: Chrysopidae), on prepupae of alfalfa leafcutting bee, Megachile rotundata (Hymenoptera: Megachilidae). Proc. Entomol. Soc. Manitoba 61:11-19.

Veith M, Lorenz M, Boland W, Simon H, Dettner K. 1994. Biosynthesis of iridoid monoterpenes in insects: Defensive secretions from larvae of leaf beetles (coleoptera: chrysomelidae). Tetrahedron 50(23):6859-6874.

Wade MR, Zalucki MP, Wratten SD, Robinson KA. 2008. Conservation biological control of arthropods using artificial food sprays: Current status and future challenges. Biological Control 45(2):185-199.

Weibel DB, Oldham NJ, Feld B, Glombitza G, Dettner K, Boland W. 2001. Iridoid biosynthesis in staphylinid rove beetles (Coleoptera: Staphylinidae, Philonthinae). Insect Biochem. Mol. Biol. 31(6/7):583-591.

Winterton SL, Hardy NB, Wiegmann BM. 2010. On wings of lace: phylogeny and Bayesian divergence time estimates of Neuropterida (Insecta) based on morphological and molecular data. Syst. Entomol. 35(3):349-378.

Wyatt TD. 2014. Pheromones and animal behavior: chemical signals and signatures: Cambridge University Press.

Zhang Q-H, Chauhan KR, Erbe EF, Vellore AR, Aldrich JR. 2004. Semiochemistry of the goldeneyed lacewing Chrysopa oculata (Neuroptera: Chrysopidae): Attraction of males to a male-produced pheromone. J. Chem. Ecol. 30(9):1849-1870.

Zhang Q-H, Schneidmiller RG, Hoover D, Young K, Welshons D, Margaryan A, Chauhan KR, Aldrich JR. 2006a. Male-produced pheromone of the green lacewing, Chrysopa nigricornis (Neuroptera: Chrysopidae). J. Chem. Ecol. 32(10):2163-2176.

Zhang Q-H, Sheng M, Chen G, Aldrich JR, Chauhan KR. 2006b. Iridodial: a powerful attractant for the green lacewing, Chrysopa septempunctata (Neuroptera: Chrysopidae). Naturwissenschaften 93(9):461-465. 
Figure 1 (on next page)

Male Chrysopa septempunctata captured in pheromone-baited trap, Shengyang, China (Zhang et al., 2006).

Chrysopa females come to the vicinity of iridodial-baited traps, but are seldom caught (Chauhan et al., 2007). 


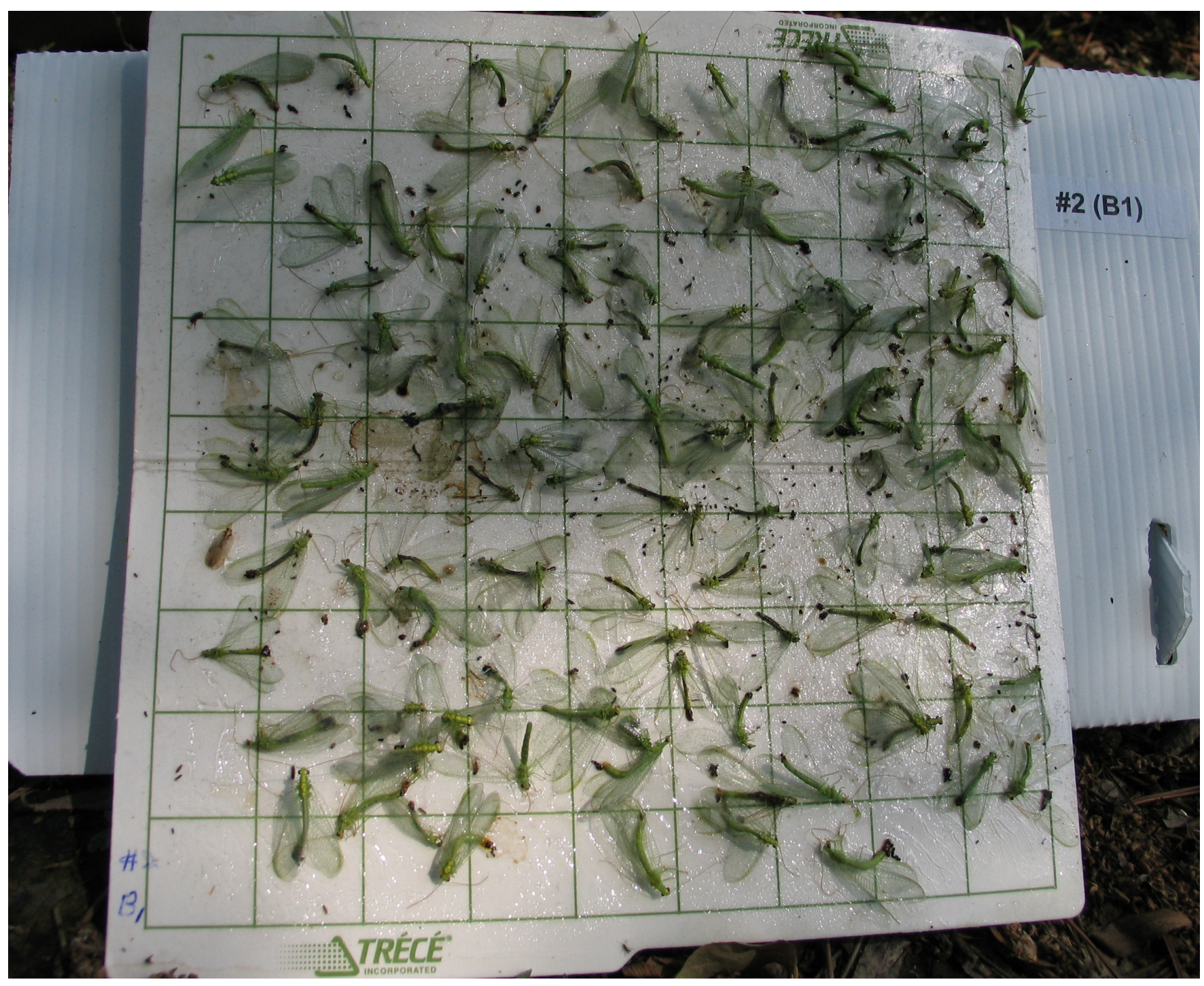


Figure 2 (on next page)

Scanning electron micrographs of the male-specific dermal glands of Chrysopa oculata.

Low temperature scan (Erbe et al., 2003) with insert showing close-up of two dermal glands. 


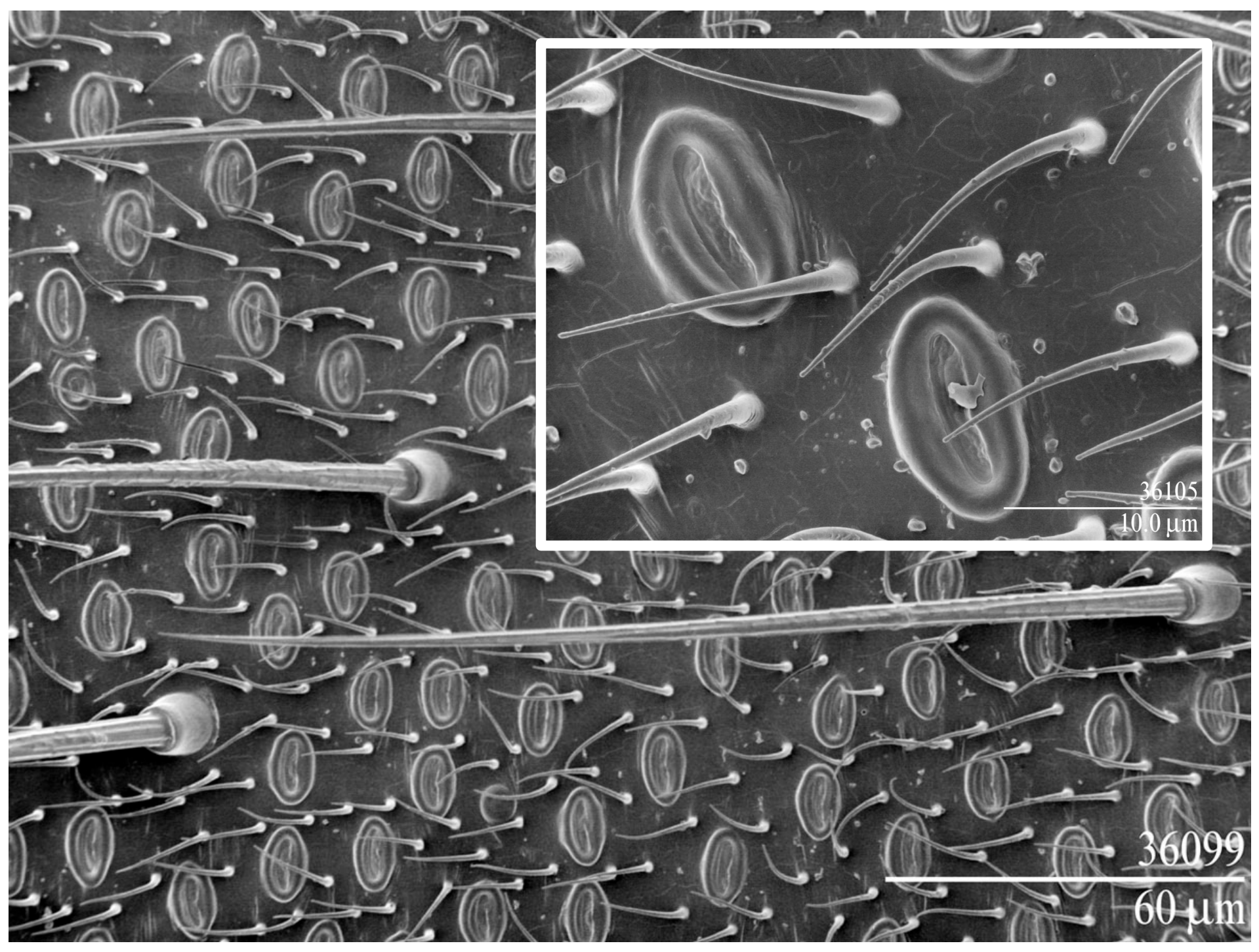


Figure 3 (on next page)

Total ion chromatograms of abdominal cuticular extracts of male Chrysopa oculata.

A) Field-collected, B) laboratory-reared and, C) laboratory-reared fed (1R,4S,4aR,7S,7aR)-

dihydronepetalactol (see Table 2). (Column $=30 \mathrm{~m}$ DB-WAXetr: $\mathbf{a}=$ nonanal $; \mathbf{b}=$ nonanol; $\mathbf{c}$ $=(\mathrm{Z})$-4-tridecene; $\mathbf{1}=(1 \mathrm{R}, 2 \mathrm{~S}, 5 \mathrm{R}, 8 \mathrm{R})$-iridodial; $\mathbf{d} \& \mathbf{e}=168 \mathrm{MW}$ isomers. $)$ 

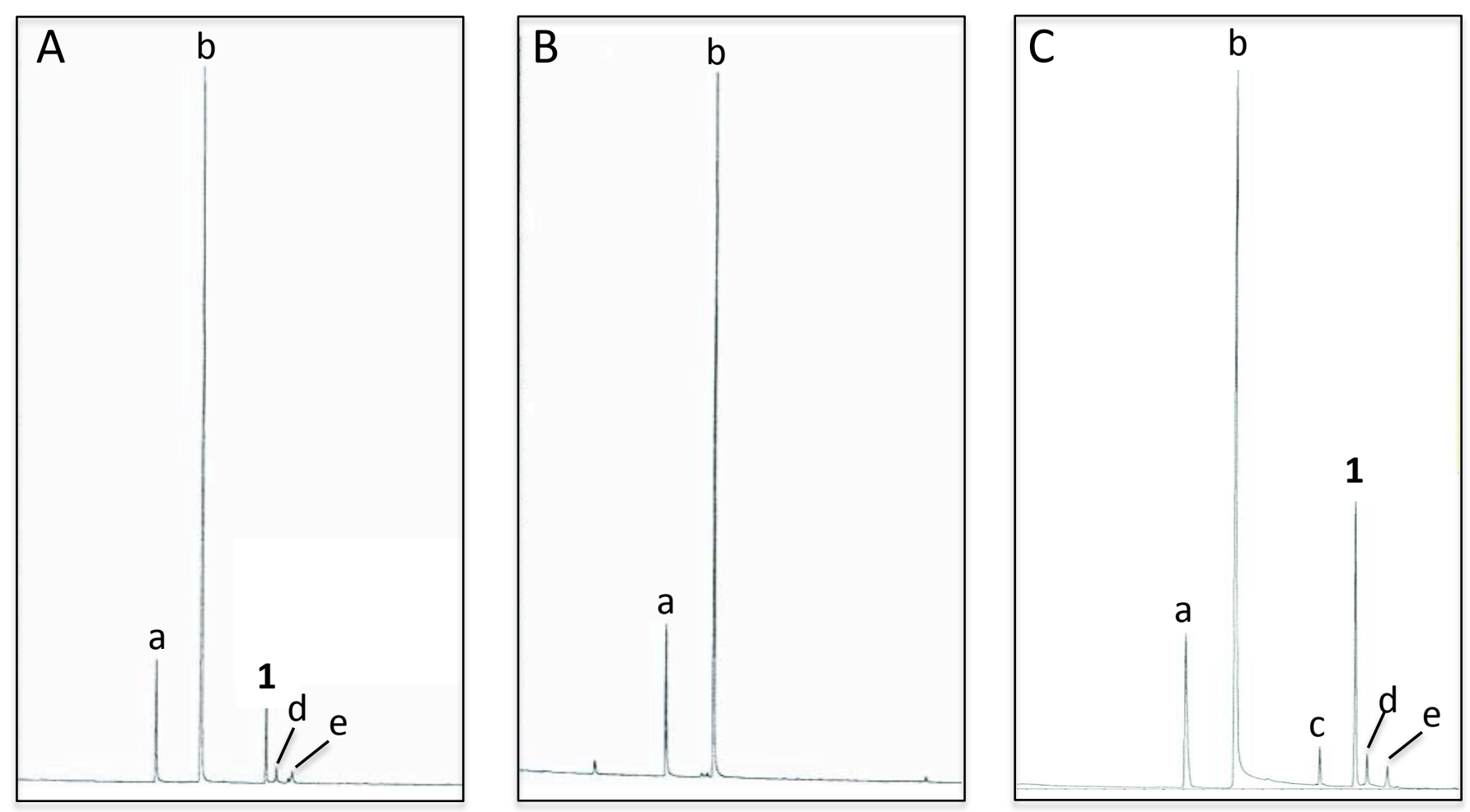


\section{Table $\mathbf{1}$ (on next page)}

\section{Volatiles from abdominal cuticle of field-collected and laboratory-reared}

\section{Chrysopa oculata males.}

Wild C. oculata males were collected by sweep net, Beltsville, Maryland, and C. oculata laboratory-reared males (see text for details) were sampled for comparisons. One C. oculata male was from a field trap baited with a lure including synthetic iridodial. Abdominal cuticle (segments 3-8) for chemical analyses were prepared as described previously (Zhang et al., 2004). 
1

\begin{tabular}{|c|c|c|c|c|c|}
\hline \multirow[b]{2}{*}{ Source / Date } & \multirow[b]{2}{*}{$\begin{array}{c}\mathbf{N} \\
\mathrm{a}\end{array}$} & \multicolumn{3}{|c|}{ Compound (\%) } & \multirow[b]{2}{*}{$\begin{array}{l}\mathbf{\%} \square \\
\sum^{\mathbf{c}}\end{array}$} \\
\hline & & Nonanal & Nonanol & $\underset{\mathrm{b}}{\text { Iridodial }}$ & \\
\hline Field / 14 May 2009 & 4 & 13.06 & 80.68 & 2.35 & 96.09 \\
\hline Field / 18 May 2009 & 2 & 15.81 & 80.16 & 2.12 & 98.09 \\
\hline Field / 22 May 2009 & 1 & 10.31 & 42.01 & 38.13 & 90.45 \\
\hline Field / 28 May 2009 & 1 & 30.09 & 50.06 & 16.11 & 96.26 \\
\hline Field / 28 May 2009 & 1 & 13.56 & 67.55 & 16.19 & 97.30 \\
\hline Field / 28 May 2009 & 1 & 8.84 & 74.88 & 14.06 & 97.78 \\
\hline Field / 1 June 2009 & 1 & 32.24 & 54.82 & 9.94 & 97.00 \\
\hline Field / 1 June 2009 & 1 & 13.69 & 65.20 & 15.53 & 94.42 \\
\hline \multicolumn{2}{|c|}{ Mean: } & 13.95 & 64.42 & 14.30 & 95.92 \\
\hline \multicolumn{2}{|c|}{ +SEM: } & 3.81 & 4.73 & 3.72 & \\
\hline $\begin{array}{l}\text { Field Trapd / } 13 \text { May } \\
2008\end{array}$ & 1 & 16.43 & 38.93 & 40.71 & 96.07 \\
\hline Lab / 27 June $2008^{\mathrm{e}}$ & 8 & 21.28 & 76.26 & 0 & 97.54 \\
\hline $\mathrm{Lab} / 13$ Aug 2008e & 5 & 21.37 & 69.34 & 0 & 90.71 \\
\hline $\mathrm{Lab} / 24$ Nov $2008^{\mathrm{e}}$ & 6 & 11.20 & 86.12 & 0 & 97.32 \\
\hline $\mathrm{Lab} / 24$ Nov $2008^{\mathrm{e}}$ & 7 & 18.60 & 75.74 & 0 & 94.34 \\
\hline $\mathrm{Lab} / 5 \operatorname{Jan} 2009^{\mathrm{f}}$ & 5 & 16.58 & 79.42 & 0 & 96.00 \\
\hline \multicolumn{2}{|c|}{ Mean: } & 17.81 & 77.38 & $\mathbf{0}$ & 95.18 \\
\hline \multicolumn{2}{|c|}{ +SEM: } & 1.88 & 1.73 & & \\
\hline
\end{tabular}

$2{ }^{\text {a }}$ In samples where $\mathrm{N}>1$, multiple males were pooled and analyzed as a single

3 sample by GC-MS on a $30 \mathrm{~m}$ DB-WaxETR column.

4 b $(1 R, 2 S, 5 R, 8 R)$-Iridodial (Chauhan et al., 2004).

$5 \quad$ e Percentage of total volatiles; nonanoic acid (poorly resolved

6 chromatographically) accounted for the majority of non-included volatiles.

7 d This $C$. oculata male was collected in a trap baited with $5 \mathrm{mg}$ of iridodial plus $1 \mathrm{mg}$ of skatole

8 per $50 \mu$ of octane to the well of gray rubber septa (5-mm sleeve-type, The West Co., Lititz,

9 PA); the trap used was as previously described (Zhang et al. 2004), and it was deployed at the

10 Agricultural Research Center-West, B Beltsville, MD.

11 e Reared singly as adults.

$12 \mathrm{f}$ Reared in a group as adults. 


\section{Table 2 (on next page)}

Compounds produced by laboratory-reared Chrysopa oculata males fed various exogenous terpenoids.

Sampling and rearing methods described in text; $1 \mu \mathrm{g} / \mu$ l test compound in honey water, analyzed by gas chromatography-mass spectrometry using a 30 m DB-WaxETR column. 
1

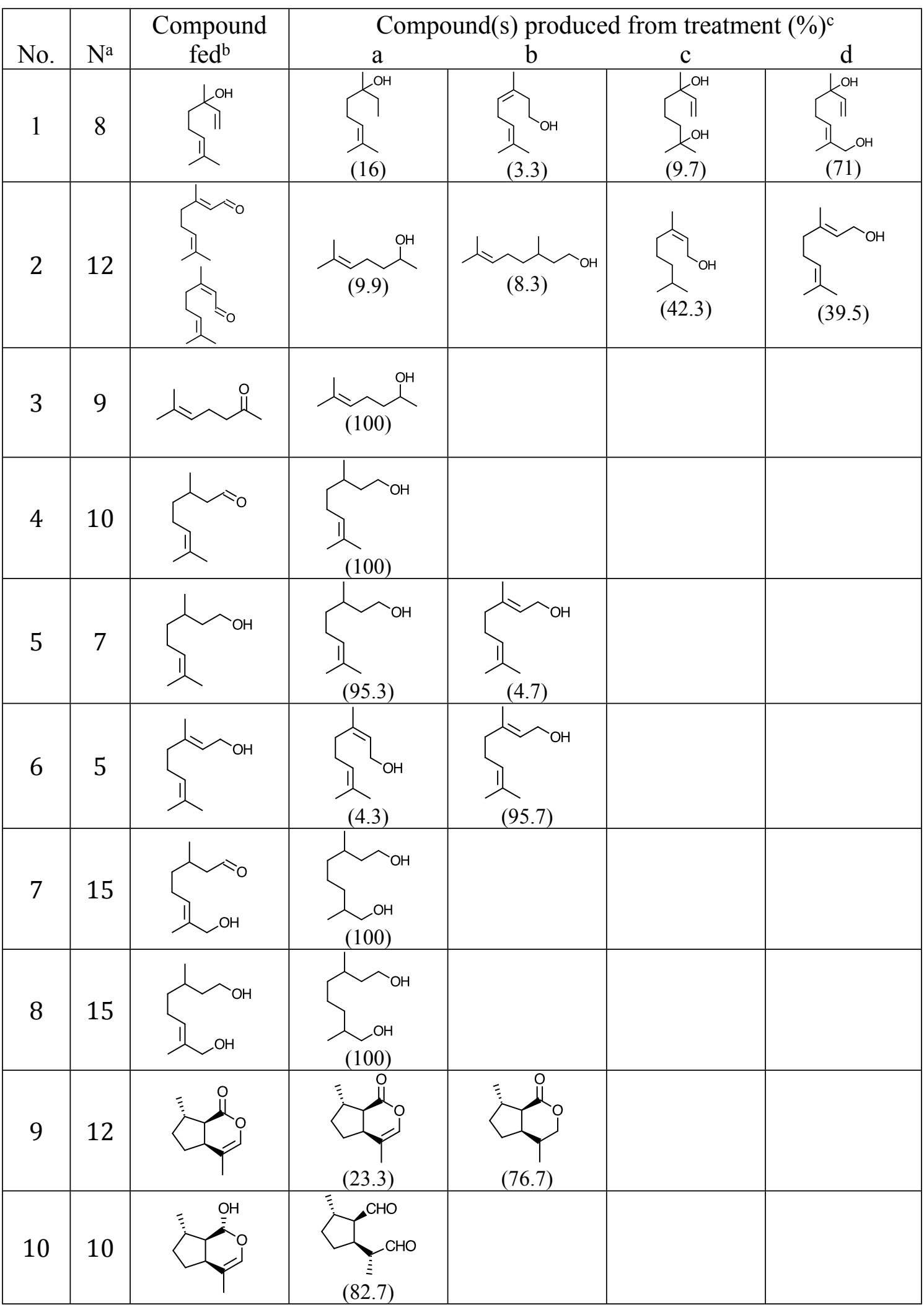

2 a Number of males pooled for analysis. 
3 b Sources of standards listed in text; 1) 3,7-dimethyl-1,6-octadien-3-ol (linalool), 2) (Z/E)-3,7-

4 dimethyl-2,6-octadienal (citral: 43\% Z-isomer, neral $+57 \% E$-isomer, geranial), 3) 6-methyl-5-

5 hepten-2-one, 4) 2,6-dimethyl-5-heptenal (citronellal), 5) 2,6-dimethyl-5-heptenol (citronellol),

6 6) (E)-3,7-dimethyl-2,6-octadien-1-ol (geraniol), 7) (E)-3,7-dimethyl-8-hydroxy-6-octen-1-al (8-

7 hydroxycitronellal), 8) (E)-2,6-dimethyloct-2-ene-1,8-diol (8-hydroxycitronellol), 9)

8 (4aS,7S,7a $R)$-nepetalactone and, 10) $(1 R, 4 S, 4 \mathrm{a} R, 7 S, 7 \mathrm{a} R)$-dihydronepetalactol. Purities of all

9 standards (except for iridodial) were $\geq 95 \%$; synthetic and natural iridodial analyzed by GC

10 existed with two later eluting $168 \mathrm{MW}$ isomers (Fig. 3; compounds $\mathrm{d}$ and e), here accounting for

$11 \quad 10.2 \%$ and $7.1 \%$, respectively, of the $168 \mathrm{MW}$ compounds.

$12{ }^{c}$ Abdominal cuticle (segments 3-8) for chemical analyses of $C$. oculata male-produced volatiles

13 were prepared as described previously (Zhang et al., 2004). Compounds produced from fed

14 precursors for which synthetic standards were available were verified by coinjections: 2 c \& $6 a$ )

15 nerol; 2d, 5b \& 6b) geraniol; 4a \& 5a) citronellol; 9a) (4aS,7S,7aR)-nepetalactone; 9b)

$16(4 \mathrm{a} S, 7 S, 7 \mathrm{a} R)$-dihydronepetalactone and, $10 \mathrm{a})(1 R, 2 S, 5 R, 8 R)$-iridodial. Other compounds were

17 tentatively identified by near matches to mass spectra of compounds in the National Institute of

18 Standards and Technology (NIST) mass spectral library: 1a) 3,7-dimethyl-6-octen-3-ol (1,2-

19 dihydrolinalool); 1b) (Z)-3,7-dimethyl-2,6-octadien-1-ol; 1c) 2,6-dimethyl-7-octene-2,6-diol; 1d)

20 (E)-2,6-dimethyl-2,7-octadiene-1,6-diol; 2a \& 3a) 6-methyl-5-hepten-2-ol; 2b) 3,7-dimethyl-6-

21 octen-1-ol.

22 Compound 7a and 8a yielded a less than a perfect match for 3,7-dimethyl-1,7-octanediol; based 23 upon previously seen glandular reactions, this compound is likely 2,6-dimethyl-1,8-octanediol. 